\title{
FAZENDA BOA VISTA: UMA PROPOSTA DE ECOTURISMO
}

\author{
Luciano Zanetti Pessôa Candiotto \\ Bolsista PET do dep. de Geografia - UFU \\ Beatriz Ribeiro Soares \\ Profa. do Dep. de Geografia - UFU
}

RESUMO: Este estudo objetiva conhecer os componentes naturais e identificar possíveis atrativos turísticos na Fazenda Boa Vista, situada no município de Prata-MG.

Palavras chaves: ecoturismo, componentes naturais, atrativos turísticos.

\section{INTRODUÇÃO}

Este estudo objetiva conhecer os componentes naturais e identificar possíveis atrativos turísticos na Bacia do Ribeirão Boa Vista, localizado no Município do Prata, Triângulo Mineiro-MG, entre as coordenadas 1918' latitude $S$ e 4855' longitude W. A presente área encontra-se inserida no Domínio Natural do Cerrado, possuindo uma beleza cênica, caracterizada por um relevo de formações residuais e por outros atrativos, tais como: sítio paleontológico, inscrições rupestres, entre outros. O processo de voçorocamento nesta área é intenso, impedindo assim, o uso do solo para determinadas culturas. Este fato chamou a atenção de pesquisadores do LAGES/UFU (Laboratório de Geomorfologia e Erosão de Solos), que iniciaram um monitoramento para essas voçorocas, com o objetivo de identificar a evolução desse processo e a partir disso controlá-lo. Nesse contexto, como maneira de aproveitamento dessas áreas naturais degradadas, optamos por elaborar uma proposta de planejamento de ecoturismo, com o intuito de minimizar os impactos ambientais e criar um manejo alternativo, pois, através de uma atividade ecoturística consciente a sustentabilidade da área poderá ser garantida, estabelecendo, assim, um equilíbrio ambiental concomitante a um desenvolvimento sócio-econômico.
A nosso ver, este trabalho insere-se numa nova concepção de manejo de áreas naturais, pois a proposta a ser desenvolvida tentará fazer do ecoturismo e do turismo rural uma atividade relacionada à educação ambiental e à conservação do meio ambiente.

\section{CONSIDERAÇÕES PRELIMINARES SOBRE PLANEJAMENTO TURÍSTICO E ECOTURISMO}

Na questão do desenvolvimento sustentável um instrumento crucial para atingir os seus objetivos é o planejamento em seus vários níveis, e na atividade turística, o mesmo também é necessário, principalmente, se for elaborado de maneira correta, considerando-se os componentes do desenvolvimento na/da estrutura do mercado turístico e dos ambientes naturais e construídos.

No que tange ao planejamento turístico, este depende diretamente de um plano maior que integre outros setores que constituem a infra-estrutura dos transportes, comunicações, segurança; e a existência de serviços de hotelaria, alimentação, lazer, etc..

No planejamento turístico várias são as etapas para sua elaboração e dentre elas destacamos: 
a) pesquisa de necessidades, que nada mais é que um diagnóstico sobre o desenvolvimento da atividade turística;

b) verificação de infra-estrutura básica, com o intuito de detectar as deficiências e propor melhorias no local;

c) envolvimento da população residente no planejamento e execução das várias etapas, para que o turismo não se torne uma atividade prejudicial aos nativos, que detém uma pequena parcela da receita gerada pelo turismo.

Através de um roteiro básico de análise de demanda, podemos propor e orientar a oferta turística, a política de marketing, de uso do solo, de meio ambiente e de preservação do patrimônio cultural e histórico, pois planejamento, desenvolvimento e operação do turismo constituem parte de estratégias de conservação e de desenvolvimento sustentável para uma região, devendo ser considerado o equilíbrio entre os fatores econômicos, ambientais e sociais.

Para cada tipo de turismo, o planejamento deverá ser específico, visando adequar os atrativos à demanda. Por exemplo, para o desenvolvimento da atividade turística em áreas naturais, é importante que sejam consideradas questões relacionadas à sua preservação; estudos sobre impactos ambientais, culturais e sócio/econômicos; para que se possa obter lucros sem agredir o meio bem como preservar a qualidade da oferta turística tanto para o visitante como para o morador. Nesse sentido, o ecoturismo vem apresentando-se como uma alternativa de conservação do meio ambiente, revitalização de determinadas áreas, bem como de sustentabilidade econômica para as populações envolvidas.

O ecoturismo surge como maior expressão da atividade turística de forma sustentável, pois, é um dos segmentos da economia que mais cresce e, sendo assim, necessita de medidas rigorosas de conservação, tanto das áreas visitadas como de sua utilização.

O Plano de Diretrizes para uma Política Nacional de Ecoturismo (1996:19), conceitua ecoturismo como:

um segmento da atividade turística que utiliza, de forma sustentável, o patrimônio natural e cultural, incentiva sua conservação e busca a formação de uma consciência ambientalista através da interpretação do ambiente, promovendo o bem estar da populações envolvidas.

A percepção mundial com relação à proteção e recuperação dos recursos naturais intensificou-se a partir dos movimentos conservacionistas empreendidos por grupos ambientalistas, forças políticas e meios de comunicação, que propiciaram ao ecoturismo uma nova base filosófica, em que o homem não aparece como elemento individualizado, mas como parte integrante da natureza.

Segundo PAGANI et al (1996: 151), o ecoturismo, tem como principais objetivos:

- evitar as grandes concentrações turísticas e a urbanização excessiva;

- integrar o turismo ao meio ambiente mediante uma arquitetura adaptada;

- preservar e valorizar o patrimônio natural, histórico e cultural;

- participação das comunidades locais;

- aquisição de consciência pelas populações locais e pelos turistas a respeito da necessidade de proteger as riquezas naturais e do patrimônio.

O ecoturismo também pode salvar o habitat e vários biomas, pois emprega 
pessoas e arrecada capital, mas também possui problemas, tais como o excesso de pessoas no local, poluição por automóveis, acúmulo de lixo, degradação das águas, etc. Se as normas pré-estabelecidas, no que tange a infra-estrutura, não forem atendidas, o meio ambiente será prejudicado, podendo sofrer sérias alterações na paisagem, na topografia, no sistema hídrico e na conservação dos recursos naturais - flora e fauna. Entretanto, se os planos de manejo de cada ecossistema forem elaborados de modo que se preserve o ambiente, respeite a população residente e destaque as particularidades dos mesmos, será possível lucrar com o meio ambiente sem destruí-lo.

A oferta de destinos ecoturísticos depende da existência de áreas de elevado valor ecológico e cultural; de sua gestão; da existência de infra-estruturas adequadas e da disponibilidade de recursos humanos capacitados.

Atualmente, o ecoturismo é o segmento do turismo que mais cresce no mundo, atingindo cerca de $10 \%$ do mercado global e por ser uma atividade de baixo impacto ambiental e atender às necessidades de lazer, proporciona aos turistas um maior conhecimento da natureza.

No Brasil, a atividade ecoturística tende a crescer cada vez mais, pois o país possui desde regiões equatoriais, ao norte, até áreas extratropicais, ao sul, que se diferenciam climática e geomorfologicamente, com uma extraordinária diversidade ecológica.

Com o adequado aproveitamento dos variados ecossistemas brasileiros, poder-seá reduzir alguns impactos negativos causados pelo turismo tradicional, devido ao perfil e às expectativas dos visitantes que normalmente viajam em pequenos grupos.

Cabe ressaltar que os ecossistemas do país, ainda são pouco explorados com fins ecoturísticos, devido à falta de infraestrutura, pessoal capacitado e de uma política de desenvolvimento do mesmos. Com o intuito de sanar diversos obstáculos que impedem o seu desenvolvimento, o Governo Federal, através da EMBRATUR e do IBAMA elaborou as Diretrizes para uma Política Nacional de Ecoturismo, que tem como objetivos básicos:

- Compatibilizar as atividades de ecoturismo com a conservação de áreas naturais;

- fortalecer a cooperação interinstitucional;

- possibilitar a participação efetiva de todos os segmentos atuantes no setor;

- promover e estimular a capacitação de recursos humanos para o ecoturismo;

- promover, incentivar e estimular a criação e melhoria da infra-estrutura para a atividade de ecoturismo;

- promover o aproveitamento do ecoturismo como veículo de educação ambiental.

Se esses objetivos forem alcançados com êxito, o Brasil poderá dar um salto no cenário mundial do Turismo, pois poucos países possuem uma diversidade tão grande de recursos naturais e ecossistemas tão variados, como a Floresta Amazônica, o Pantanal, a Mata Atlântica, a Caatinga, os Campos do Sul, os Manguezais, as Zonas Costeiras e o Cerrado. Todos tem particularidades e, se forem planejados com fins ecoturísticos, deverão possibilitar a sustentabilidade dessas áreas, preservandoas para o futuro.

\section{BACIA DO RIBEIRÃO BOA VISTA: ASPECTOS NATURAIS POSSIBILIDADES TURÍSTICAS}

O conhecimento dos aspectos físicos da área pesquisada para a atividade turística é fundamental para se determinar com 
clareza o tipo de uso e manejo do local, ou seja, como pode ser explorada e o que deve ser preservado, o tipo de atividade econômica a ser desenvolvida, com o intuito de minimizar os impactos negativos, pois é necessário para manter a qualidade dos atrativos à visitação de turistas, principalmente no ecoturismo e turismo rural, que dependem da preservação da natureza para seu desenvolvimento e sustentabilidade.

A educação ambiental é um ponto chave no desenvolvimento do turismo em áreas naturais, pois com a conscientização dos turistas e da população residente, há uma maior facilidade na preservação dos recursos naturais, fazendo com que a degradação tenda a minimizar-se.

Desse modo, ao se trabalhar com turismo em áreas naturais é importante mostrar aos turistas a necessidade de respeitar e preservar o meio ambiente, através de palestras ministradas antecipadamente, folders com informações da área, painéis no local, além das informações complementares que o guia passa aos turistas durante a visitação.

A caracterização física dos residuais do município do Prata foi realizada com base no trabalho de PEREIRA (1996) que mostra que a região estudada, assim como todo o Triângulo Mineiro, está inserida na Bacia Sedimentar do Paraná, onde predominam arenitos do Grupo Bauru, com texturas variadas. A Formação Marília, que predomina nos residuais, é uma subdivisão do Grupo Bauru e encontra-se sobre os basaltos da Formação Serra Geral.

No topo dos relevos residuais da Bacia do Ribeirão Boa Vista, os arenitos da Formação Marília encontram-se na sua fácie conglomerática, ou seja, na fácie mais resistente, pois os arenitos finos e grosseiros apresentam-se com cimentação carbonática e silicificada.
No sopé dos relevos residuais que englobam o Ribeirão Boa Vista e seus afluentes, nascem as veredas que são indicadores da existência de camadas de materiais mais resistentes e impermeáveis logo abaixo da superfície das rampas, deixando as margens dos córregos encharcados e formando uma larga faixa de campo hidromórfico no leito da drenagem.

Além dessa caracterização geológica, é importante ressaltarmos a presença de inscrições rupestres por civilizações antigas, em algumas escarpas dos residuais, localizados na Fazenda Monjolinho, bem como fósseis de dinossauros com 100 milhões de anos, segundo o Museu Arqueológico de Peirópolis - MG.

A geomorfologia da bacia do Ribeirão Boa Vista é de fundamental importância para esse estudo, pois maior atrativo da área são as formações dos relevos residuais que possuem uma beleza cênica a ser destacada. Os estudos de BACCARO (1991), colocam o município do Prata com as seguintes unidades geomorfológicas:

- A unidade de relevo medianamente dissecado com topos aplainados em torno de $600-750 \mathrm{~m}$ de altitude com formas convexas e vertentes entre $3-15^{\circ}$ de declividades. A cobertura arenítica da Formação Marília do Grupo Bauru, recoberta pelos sedimentos inconsolidados do Cenozóico sobreposto, ao arenito da Formação Adamantina, o qual apresenta uma variação de areias médias e finas sem a presença de agregados, tornando-o extremamente friável. E logo depois está o basalto da formação Serra Geral, onde estão os talvegues dos principais rios do município: rio Tijuco e rio da Prata.

- Áreas de relevos residuais relacionadas às estruturas cujo as bordas são escarpadas com altura de até $150 \mathrm{~m}$, de contornos irregulares, com declividade entre 30 - $90^{\circ}$, correspondendo aos divisores de água das principais bacias da região. Estas são 
"serras" com topos variando de 850 - 700m em forma de tabuleiro e mesa.

As serras e relevos residuais da bacia do Ribeirão Boa Vista, alinham-se paralelamente à drenagem dos principais rios, cujo as nascentes encontram-se rodeadas pelas serras do Salto, Bonito e Boa Vista, com altitudes que variam de 750 a $550 \mathrm{~m}$, ocasionando desníveis entre o topo das serras e as barrancas dos cursos d'água de $150 \mathrm{~m}$.

Os relevos residuais apresentam forte dissecação. Os processos erosivos mais freqüentes são: solapamento, queda de blocos e escorregamento de material. Sob o relevo residual, existem níveis de patamares diferenciados, com estruturas e resistências variadas.

A vegetação nativa diferencia-se um pouco do cerrado típico, pois os solos possuem teores altos de $\mathrm{Ph}$ e matéria orgânica nas primeiras camadas, formando assim, uma vegetação de porte mais alto, com copas frondosas e troncos mais retos.

Desta forma, a vegetação da área é caracterizada como cerradão/mata de encosta/mata ciliar, que atualmente são encontradas em alguns pontos no sopé das serras, borda de escarpas, antigas voçorocas, nos leitos d'água e espraiadas em manchas pelas áreas de pastagens.

O restante da área é ocupado por pastagens que, quando não possuem vegetação arbustiva, aceleram os processos erosivos. Nas áreas mais desmatadas no passado, formaram-se as grandes voçorocas, que tornaram-se habitat de espécies faunísticas e florísticas, pois foram abandonadas pelos proprietários, devido a impossibilidade de uso.

O clima da região apresenta basicamente duas estações distintas, sendo o inverno seco, que vai de abril até meados de setembro, e a primavera/verão chuvoso, que ocupa os meses restantes.

Devido a concentração das chuvas, estas apresentam-se de forma torrencial, ou popularmente conhecidas como chuvadas, que deslocam sedimentos do topo dos residuais até o sopé das serras, ocasionando ravinamentos e voçorocamentos devido a abrasividade dos sedimentos. Assim, as veredas que situam-se a jusante das voçorocas encontram-se assoreadas.

Para o turismo, o fator climático é importante para o conforto do turista. Portanto, é aconselhável a visitação no período seco, pois na época das chuvas, as mesmas são muito fortes, impedindo várias atividades de lazer e a própria visualização da paisagem limpa.

A drenagem é um importante aspecto na esculturação do relevo, bem como para o desenvolvimento da atividade turística, principalmente nesta área onde a beleza cênica dos residuais é o maior atrativo.

As principais drenagens do Triângulo Mineiro obedecem um paralelismo contínuo, que indica interferências tectônicas, como os rios: Tijuco, Prata, Peixoto, Verde ou Feio e o rio Grande.

Nos relevos residuais há maior concentração de água, pois as drenagens surgem no interior das serras, formando assim os anfiteatros com forte dissecação dos mesmos..

Apesar dessa drenagem nos residuais, a área pesquisada sofre com a falta de um canal de água perene. É necessário uma certa abundância de água para o desenvolvimento do turismo, pois como a área tem um clima quente, banhos e atividades aquáticas são essenciais para satisfazer os turistas. 
Diante da realidade apresentada quanto aos aspectos naturais, a fazenda Boa Vista, localizada na bacia do Ribeirão Boa Vista apresenta duas principais feições para o turismo que são o Ecoturismo e o Turismo Rural. A primeira visa estabelecer uma interação entre o homem e a natureza, de maneira sustentável, despertando no mesmo uma consciência ambientalista voltada ao conhecimento do meio ambiente e de suas formas de preservação.

A segunda é voltada à interação do homem, geralmente urbano, com o estilo de vida do campo, num local preservado e simples, onde são valorizados culturas, culinária, animais, além das plantações, hortas e pomares. O cotidiano do campo é vivido através do desenvolvimento correto do turismo rural, que não exige muitos investimentos por parte do proprietário.

Além desses dois, o turismo de aventura apresenta-se como uma outra opção, através das escaladas e do rapel, ou seja, a descida das escarpas com cordas e equipamentos especiais. Dependendo das condições climáticas, o vôo de Asa Delta se faz possível.

A área também pode servir ao turismo para a terceira idade, ou seja, para os idosos que procuram um lugar tranqüilo, bonito $e$ agradável para descanso e lazer.

\section{PROPOSTA PRELIMINAR PARA UTILI- ZAÇÃO DA ÁREA ATRAVÉS DO TURISMO}

O plano para o desenvolvimento do ecoturismo na Fazenda Boa Vista é uma alternativa de uso do local, que tem como principal atividade a pecuária leiteira. Para prática do ecoturismo e do turismo rural, procuramos estabelecer medidas de ação a curto, médio e longo prazo. Estas medidas não obedecerão um tempo pré estabelecido, mas deverão ser implementadas concomitante ao desenvolvimento do turismo na área.

\section{a) Propostas a curto prazo}

As atividades que já podem ser implementadas a curto prazo, geralmente, são aquelas ligadas diretamente ao meio natural da área, ou seja, as caminhadas aos residuais que não necessitam de equipamentos, apenas em alguns pontos 0 uso de uma corda se faz necessário para sua escalada. No entanto, para a prática do rapel pelas escarpas erosivas até o sopé dos residuais, há a exigência de equipamentos adequados e seguros.

As cavalgadas também são outro atrativo, pois as áreas de pastagens são planas e com algumas árvores grandes preservadas, sem contar a beleza da paisagem, que oferece tranqüilidade ao visitante. Quem preferir pode levar sua bicicleta e pedalar pela fazenda.

A culinária caseira é outra grande atração pois os doces e quitutes feitos com produtos da própria fazenda deixam qualquer um impressionado. O queijo, pudim de leite, pão-de-queijo e sucos são alguns exemplos da culinária mineira tradicional. A coleta de frutos completa este contato com o campo.

As informações básicas de educação ambiental, conhecimento e conduta na área devem ser passadas à todos os visitantes, através de folders, mapas, palestras, etc. No caso de um turismo mais educativo, essas informações devem ser aprofundadas, conforme os anseios dos turistas.

Como principais medidas, sugerimos uma reforma da casa sede, que já vem ocorrendo; a instalação de duchas, devido a escassez de locais para banhos e a plantação de pomares e árvores ornamentais.

Conforme o desenvolvimento da atividade turística na Fazenda, se faz 
necessário uma melhoria na estrada de acesso, que poderia ser realizada através da colocação de pedregulhos, pois, principalmente na época das chuvas o caminho se apresenta escorregadio.

\section{b) Propostas a médio prazo}

As medidas propostas a médio prazo, devem ser realizadas quando a fazenda já tiver um número constante de visitantes, ou seja, quando a prática do turismo estiver difundida. As atividades são, basicamente, as mesmas, mas nessa etapa, a melhoria da infra-estrutura é um ponto importante.

A construção de represas ou lagos é uma das principais medidas e outro atrativo que será muito utilizado, devido ao clima quente, que vigora por boa parte do ano. $\mathrm{O}$ local proposto para esta implantação, situase numa área de solo hidromórfico, perto da drenagem e próximo à sede, conforme indica o mapa.

Entre a sede e a provável represa, seria interessante a construção de quiosques com churrasqueiras, bancos e mesas para churrasco ou lanche. É necessário ressaltar que a área deve ter uma simples rede de água para beber, lavar-se e cozinhar, bem como lixeiras esparsas, com informações sobre educação ambiental, enfatizando a questão do lixo. Um fator a ser destacado, diz respeito a separação do lixo, com o intuito de reaproveitar o que for orgânico e biodegradável, além de não deixar plásticos e latas espalhados pela Fazenda.

Se a visitação estiver aumentando e, consequentemente as cavalgadas, o proprietário deve investir na compra de cerca de mais 10 cavalos e melhorar o estábulo, que é mais um local a ser aproveitado para o turismo rural.

A criação de um campo de futebol e de um pequeno posto de socorros médicos são as opções que complementam as medidas à médio prazo.

\section{c) Propostas a longo prazo}

Essas medidas, assim como as outras, devem acompanhar o nível de crescimento do turismo. Apresentamos três propostas com o intuito de consolidar a propriedade ao ecoturismo e turismo rural. Cabe ressaltar que o plano não é fechado e, portanto propício à mudanças que visem o melhor desenvolvimento desta atividade.

A primeira seria a construção de um alojamento para abrigar cerca de 50 pessoas. Estes deveriam ser simples, mas com banheiros, água, energia elétrica e acomodações confortáveis. Neste bloco. poderia haver uma sala para confraternizações e jogos, que contivesse painéis e fotos da área, valorizando sua beleza e conhecimento proporcionado.

A construção de uma represa artificial para pesca é mais uma alternativa. A implantação de um pesque-pague diverte e tranqüiliza o turista e propicia lucro ao proprietário. O local para esta represa ainda não foi definido. Outras construções com pequenas lojas de doces e artesanato, bem como um museu sobre a história e artefatos da área, evidenciariam os aspectos culturais e proporcionariam uma integração entre os turistas e a população residente.

A área tem um potencial turístico que é destacado por sua beleza cênica, mas nunca foi pensada sob esse ponto de vista.. Com este plano, o proprietário da fazenda poderá avançar em direção a um turismo educativo, lucrativo e sustentável, que é a grande meta das gerações atuais no que diz respeito ao turismo. 


\section{REFERÊNCIAS BIBLIOGRÁFICAS}

BACCARO, C. A. D. Unidades geomorfológicas do Triângulo Mineiro: Estudo Preliminar. Sociedade \& Natureza. Uberlândia: EDUFU, ano 03, no 05/06, p. 37-42, jan/ dez, 1991.

BARRETO, M. Planejamento e organização em turismo. Campinas: Papirus, 1991. $108 \mathrm{p}$.

BURSZTYN, M. (org.). Para pensar o desenvolvimento sustentável. São Paulo: Brasiliense, 1993. 161 p.

CASTELLI, G. Turismo: atividade marcante do século XX. Caxias do Sul: EDUNI, 1986. $146 \mathrm{p}$.

LEMOS, A. I. G. (org.). Turismo: impactos socioambientais. São Paulo: Hucitec, 1996. 302 p.

PLANO de diretrizes para uma política nacional de Ecoturismo, Brasília: 1996, mimeo.

PELLEGRINI, A. F. Ecologia, cultura e turismo. Campinas: Papirus, 1993. 190 p.

PEREIRA, K. G. O. As unidades geomorfológicas na área dos relevos residuais no município do Prata - MG. Uberlândia: DEGEO/UFU, 1996. 63 p. (Monografia).

RODRIGUES, A. A. B. Geografia e Turismo: Notas introdutórias. In: Revista Geografia. São Paulo: EDUSP, n 6, p. 71-82, 1992.

Geografia do Turismo como disciplina da licenciatura em Geografia. São Paulo, s/d. (mimeo).

SACHS, Y. In: BUR SZTYN, Marcel (org.). Para pensar o desenvolvimento sustentável. São Paulo: Brasiliense, 1993. p. 29-56. 